\title{
UJI KEMAMPUAN ANTAGONISME KHAMIR ASAL DAUN JATI (Tectona grandis) TERHADAP KAPANG PENGKONTAMINAN PADA PAKAN TERNAK AYAM
}

\author{
Hilma Dianti Marham ${ }^{1 *}$, Yoswita Rustam ${ }^{1}$, dan Dalia Sulkmawati ${ }^{1}$ \\ ${ }^{1}$ Prodi Biologi, Fakultas Matematika dan Ilmu Pengetahuan Alam, Universitas Negeri Jakarta (UNJ), Jakarta \\ Timur. Indonesia \\ *E-mail: hilmadianti06@gmail.com
}

\begin{abstract}
Antagonism is the interaction that occurs when a microorganism interfere with the growth of other microorganisms. One of the microorganisms that have antagonistic ability is yeast. The research aims to determine the ability of antagonism yeast derived from the leaves of teak (Tectona grandis) as an agent for controling mold from poultry feed is Aspergillus sp., Fusarium sp., and Penicillium sp. Tests carried out using the method of antagonism co-culture in medium Potato Dextrose Broth (PDB) during the four days of incubation temperature of $27-28^{\circ} \mathrm{C}$. The results showed that yeasts have antagonism activity against Aspergillus sp., Fusarium sp., and Penicillium sp. shown by mycelial growth inhibition and sporulation. Coculture method results obtained 5 potential yeastisolates $\left(T_{3} D_{2} D U 1.7, T_{4} D_{2} W_{2} J_{2}, T_{4} D_{2} D U 2.1, T_{4} D_{1} D U 2.1, T_{5} D_{1} D U 2.2\right)$.
\end{abstract}

Keywords: Antagonism, Co-culture method, yeast phylloplane, mold.

\section{PENDAHULUAN}

Pakan adalah campuran dari berbagai macam bahan organik maupun anorganik untuk ternak yang berfungsi sebagai pemenuhan kebutuhan zat-zat makanan dalam proses pertumbuhan (Suprijatna et al, 2005). Permasalahan yang ditemukan dalam produk pakan ternak adalah adanya pertumbuhan mikroorganisme. Pertumbuhan mikroorganisme dalam pakan ternak dapat mengakibatkan perubahan fisik atau kimia yang tidak diinginkan, sehingga bahan pangan tersebut tidak layak dikonsumsi. Salah satu mikroorganisme pengkontaminan pada pakan ternak ayam adalah kapang. Kapang pengkontaminan pada pakan ternak ayam berasal dari genus Fusarium, Penicillium, Aspergillus, Thrichoderma, Cladosporium, Monilia (Angulo, 2004).

Kapang pengkontaminan pakan ternak dapat menghasilkan senyawa mikotoksin. Pencegahan pertumbuhan kapang pengkontaminan pada pakan ternak dilakukan dengan mencampurkan antibiotik sintetik (Angulo et al., 2004 ). Pemakaian antibiotik sintetik secara berlebihan dapat membunuh bakteri penting yang ada dalam saluran pencernaan hewan ternak, sehingga pencernaan hewan ternak akan terganggu.

Upaya untuk menghambat pertumbuhan kapang pengkontaminan pada pakan ternak secara alami perlu dilakukan. Bahan alami yang dapat digunakan dalam menghambat pertumbuhan kapang adalah khamir. Khamir memiliki kemampuan antagonisme yang dapat menghambat pertumbuhan beberapa mikroorganisme termasuk kapang patogen (Golubev, 2006). Mekanisme penghambatan khamir antagonis terhadap kapang patogen dapat terjadi melalui: kompetisi ruang dan nutrien, antibiosis, parasitisme, dan predasi (Pimenta et al., 2007). 
Penelitian pengujian antagonisme khamir yang diisolasi dari daun tanaman jati terhadap kapang pengkontaminan pakan ternak ayam belum pernah dilakukan. Penelitian bertujuan untuk mengetahui potensi isolat khamir dari daun jati dalam menghambat pertumbuhan kapang pengkontaminan pada pakan ternak ayam.

\section{METODE}

\section{SAMPEL PENELITIAN}

Sampel yang digunakan adalah khamir yang berasal dari daun Jati. Khamir belum teridentifikasi dan dituliskan dengan kode pada saat penelitian. Khamir ini terdiri 21, yaitu : $\mathrm{T}_{1} \mathrm{D}_{1} \mathrm{WU} 2.2(3), \mathrm{T}_{1} \mathrm{D}_{2}$ WU 1.4, $\mathrm{T}_{1} \mathrm{D}_{1} \mathrm{WU} 2.2 \mathrm{a}$, $\mathrm{T}_{2} \mathrm{~W}_{2}, \mathrm{~T}_{2} \mathrm{D}_{1}$ WU 2.8, $\mathrm{T}_{2} \mathrm{D}_{1}$ WU 2.6, $\mathrm{T}_{2} \mathrm{D}_{1} \mathrm{~W} 2.8, \mathrm{~T}_{3} \mathrm{D}_{2} \mathrm{WU} 1.3$ (1), $\mathrm{T}_{3} \mathrm{D}_{2} \mathrm{DU} 1.7, \mathrm{~T}_{3} \mathrm{D}_{2} \mathrm{DU} 2.2, \mathrm{~T}_{4} \mathrm{D}_{2} \mathrm{WU}_{2}, \mathrm{~T}_{4} \mathrm{D}_{1}$ DU2, $\mathrm{T}_{4} \mathrm{D}_{2}$ WU 1.5, $\mathrm{T}_{4} \mathrm{D}_{1}$ WU 1.3, $\mathrm{T}_{4} \mathrm{D}_{2} \mathrm{DU} 2.2, \mathrm{~T}_{4} \mathrm{D}_{2}$-DU 2.1, $\mathrm{T}_{4} \mathrm{D}_{2}$ WU 1, $\mathrm{T}_{4} \mathrm{D}_{1} \mathrm{DU} 2.1, \mathrm{~T}_{5} \mathrm{D}_{2}$ WU 1.5, $\mathrm{T}_{5} \mathrm{D}_{2} \mathrm{WU}$ 2.4, $\mathrm{T}_{5} \mathrm{D}_{1} \mathrm{DU} 2$. Kapang yang digunakan berasal dari hasil isolasi pada pakan ternak ayam di daerah Bogor. Kapang yang digunakan antara lain: Aspergillus sp., Fusarium sp., dan Penicillium sp.

\section{PEMBUATAN MEDIA}

Media yang digunakan terdiri dari Potato Dextrose Agar (PDA) dan Potato dextrose Broth (PDB). Media PDA digunakan sebagai medium permurnian kapang dan khamir, pembuatan stock dan working culture kapang dan khamir di. Media PDB digunakan sebagai medium fermentasi co-culture. Medium dibuat berdasarkan cara yang tertera pada kemasan medium.

\section{STERILISASI PERALATAN DAN MEDIUM}

Cawan petri dimasukkan ke dalam plastik tahan panas. Labu erlenmeyer berisi medium diberi label dan ditutup dengan sumbat kapas yang dibalut kertas yellow pages. Tabung reaksi berisi medium diberi sumbat kapas, dan dimasukkan ke dalam gelas beaker yang kemudian ditutup dengan kertas yellow pages. Seluruh peralatan dan medium disterilisasi dengan autoklaf pada suhu $121^{\circ} \mathrm{C}$ dan tekanan 2 atm selama 15 menit.

\section{PEMURNIAN KHAMIR DAN KAPANG}

Pemurnian khamir dilakukan berdasarkan Benson (2001) dengan menggunakan quadrant streak method. Khamir diinokulasikan menggunakan jarum tanam bulat khamir digoreskan di empat kuadran pada permukaan medium. Inkubasi isolat selama 48 jam dengan suhu $28^{\circ} \mathrm{C}$. Pemurnian isolat kapang dilakukan berdasarkan Cappucino \& Sherman (2001) dengan cara quadrant streak. Spora kapang diinokulasikan menggunakan jarum tanam tusuk pada medium PDA. Inkubasi isolat selama 4-7 hari pada suhu $28^{\circ} \mathrm{C}$.

\section{PEMBUATAN STOCK CULTURE DAN WORKING CULTURE}

Khamir dan kapang yang telah murni ditransfer ke medium PDA miring di dalam tabung reaksi. Isolat diinkubasi pada suhu $28^{\circ} \mathrm{C}$ hingga terjadi pertumbuhan. Isolat kapang dan khamir digunakan sebagai working culture dan stock culture disimpan pada suhu sekitar $4^{\circ} \mathrm{C}$ dalam lemari pendingin.

\section{PENGUJIAN SUHU}

Pengujian suhu dilakukan dengan menggunakan cawan petri yang berisi medium PDA. Cawan petri yang berisi medium PDA dibagi menjadi 4 daerah kuadran. Setiap kuadran digoreskan satu kode isolat khamir berumur 
48 jam sebanyak 10 gores. Isolat khamir di goreskan pada dua cawan petri. Cawan petri pertama diinkubasi pada suhu $27-28^{\circ} \mathrm{C}$ dan cawan petri ke dua diinkubasi pada suhu $37^{\circ} \mathrm{C}$ selama 48 jam.

\section{PENGAMATAN MORFOLOGI KHAMIR}

Pengamatan morfologi khamir secara makroskopik yang ditumbuhkan pada medium padat berdasarkan Kurtzman \& Fell (1998). Pengamatan morfologi khamir secara makroskopik adalah tekstur, warna, permukaan, profil, dan tepi koloni. Pengamatan morfologi mikroskopik khamir meliputi, bentuk pertunasan, bentuk sel, dan keberadaan hifa (Yudapati, 2012).

\section{PENGAMATAN MORFOLOGI KAPANG}

Kapang diidentifikasi berdasarkan Samson et al., (2011) dan Sjamsuridzal et al., (2006). Identifikasi kapang melalui pengamatan karakter morfologi secara makroskopik dan mikroskopik. Pengamatan makroskopik kapang meliputi: permukaan koloni (granular, seperti tepung, menggunung, licin), tekstur koloni, zonasi, daerah tumbuh, garis-garis radial dan konsentris, warna balik koloni (reverse color), dan tetes eksudat (exudate drops).

Pengamatan secara mikroskopis menggunakan metode henric's slide culture. Pengamatan mikroskopik kapang meliputi ada tidaknya spora seksual dan spora aseksual, struktur penghasil spora seksual dan spora aseksual, bentuk dan jenis spora, jenis hifa, ukuran hifa, septa pada hifa, ada tidaknya metula dan vesikel (Gandjar et al.,1999).

\section{PENGAMATAN JUMLAH KHAMIR DAN SPORA KAPANG}

Enumerasi khamir dan spora kapang dilakukan menggunakan metode TPC (Total Plate Count) berdasarkan Hogg (2005). Isolat khamir ditumbuhkan dalam medium PDA miring dengan metode streak. Biakan dimasukkan ke dalam akuadest steril $5 \mathrm{ml}$, suspensi dihomogenkan menggunakan vorteks. Suspensi sel khamir kemudian di encerkan hingga tingkat pengenceran $10^{-5}, 10^{-6}$, dan $10^{-7}$. Sebanyak $0,1 \mathrm{ml}$ dari setiap suspensi yang telah diencerkan, dituangkan pada medium PDA di cawan petri dan disebar menggunakan spatel Drygalsky. Inkubasi selama 48 jam pada suhu $28^{\circ} \mathrm{C}$.

Isolat kapang ditumbuhkan dalam medium PDA miring dengan metode streak. Biakan dimasukkan ke dalam akuadest steril $5 \mathrm{ml}$. Suspensi kemudian di homogenkan menggunakan vorteks. Suspensi spora kapang kemudian di encerkan hingga faktor pengenceran $10^{-4}, 10^{-5}$, dan $10^{-6}$. Sebanyak $0,1 \mathrm{ml}$ dari setiap suspensi yang telah diencerkan, dituangkan pada medium PDA di cawan petri dan disebar menggunakan spatel Drygalsky. Biakan kapang diinkubasi selama 7 hari pada suhu $28^{\circ} \mathrm{C}$. Perhitungan Colony Forming Unit (CFU) dengan rumus berikut:

$$
\text { Jumlah CFU/ml }=\frac{\text { Jumlah rata-rata koloni yang tumbuh }}{\text { Volume inokulum } X \text { faktor pengenceran }}
$$

\section{PENGUJIAN ANTAGONISME DENGAN METODE CO-CULTURE}

Pengujian antagonisme menggunakan metode co-culture berdasarkan Handarini (2009). Biakan khamir berumur 48 jam dikerik dan disuspensikan dalam $5 \mathrm{ml}$ PDB steril, kemudian dihomogenkan menggunakan vorteks. Sebanyak satu ml suspensi sel khamir ditambahkan ke dalam $18 \mathrm{ml}$ PDB.

Kemudian biakan ditumbuhkan dengan pengocokan secara resiprokral $100 \mathrm{rpm}$ dengan shaker pada suhu ruang selama 8 jam. Biakan kapang berumur 4 hari dikerik dan disuspensikan dalam 5 ml PDB steril, kemudian dihomogenkan menggunakan vorteks. Sebanyak satu ml suspensi spora kapang ditambahkan ke dalam $18 \mathrm{ml}$ PDB 
yang telah ditumbuhi oleh khamir berumur 8 jam. Medium diinkubasi pada suhu $28^{\circ} \mathrm{C}$ selama empat hari dalam keadaan fermentasi diam. Parameter yang diamati pada isolat khamir berupa pembentukan pelikel, ada tidaknya endapan khamir, warna endapan, perubahan $\mathrm{pH}$, dan perubahan berat medium. Pertumbuhan kapang diamati dengan melihat pembentukan hifa atau miselium, sporulasi, warna koloni, dan perubahan $\mathrm{pH}$.

\section{HASIL DAN PEMBAHASAN}

\section{PENGUJIAN SUHU}

Khamir yang digunakan dalam penelitian adalah isolat khamir daun jati yang merupakan hasil isolasi dari penelitian sebelumnya (Suci, 2012). Sebanyak 21 isolat khamir dilakukan pengujian suhu. Hasil pengujian menunjukkan semua isolat khamir tumbuh pada suhu ruang $\left(27-28^{\circ} \mathrm{C}\right)$ dan terdapat sebelas isolat khamir yang tumbuh pada suhu $37^{\circ} \mathrm{C}$.

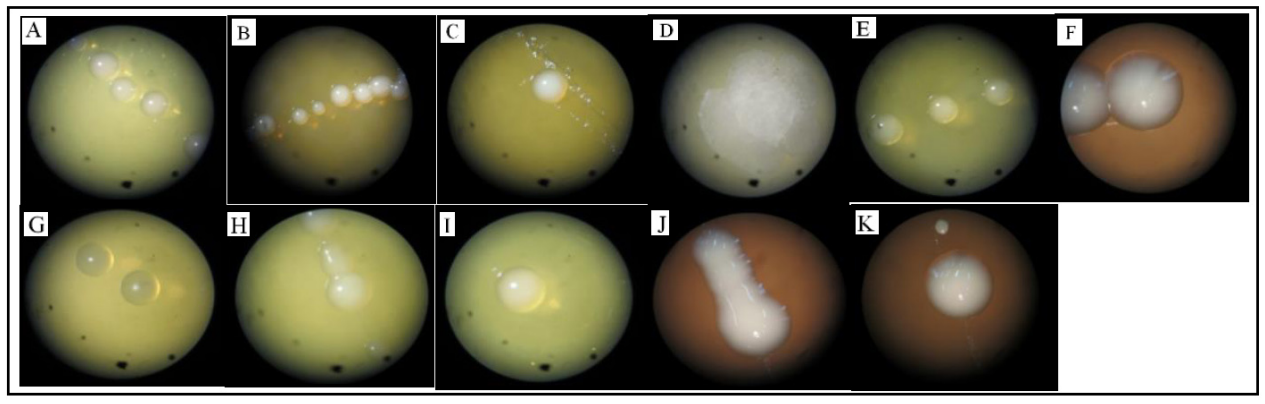

Gambar 1. Morfologi makroskopik isolat khamir asal daun jati pada medium YMA berumur 48 jam pada suhu 27-28 ${ }^{\circ}$. A: T1D1 WU 2.2 a, B: T3D2 DU 1.7 , C: T4D2 WU2J2, D: T4D2 DU 2.2 , E: T4D2-DU 2.1, F: T4D1 DU 2.1, G: T3D2 DU 2.2, H: T5D2 WU 1.5, I: T5D2 WU 2.4, J: T5D2 DU 1.1, K: T5D1 DU 2.2 [Dokumentasi pribadi].

Adanya pertumbuhan khamir pada suhu $37^{\circ} \mathrm{C}$ menyatakan bahwa isolat khamir tersebut diduga bersifat patogen. Sukmawati (2014), menyatakan bahwa pertumbuhan khamir asal daun tumbuhan saeh (Broussonetia papyrifera) pada suhu $37^{\circ} \mathrm{C}$ mengindikasikan kemampuan khamir tersebut dapat hidup pada tubuh manusia dan hewan, sehingga khamir tersebut diduga dapat menyebabkan penyakit pada manusia dan bersifat patogen.

\section{PENGAMATAN MAKROSKOPIK DAN MIKROSKOPIK KHAMIR}

Sebanyak sebelas isolat khamir yang tumbuh pada suhu ruang $\left(27-28^{\circ} \mathrm{C}\right)$ hasil dari pengujian suhu, dilakukan pengamatan secara makroskopik dan mikroskopik pada medium YMA dengan umur 48 jam. Pengamatan makroskopik khamir didominasi dengan khamir tekstur mucoid (berlendir) dan berpigmen (krem dan merah muda). Khamir yang berasal dari permukaan daun umumnya memiliki pigmen yang beragam. Lindow dan Brandl (2003), menyatakan bahwa permukaan daun didominasi dengan khamir berpigmen. Khamir memiliki tekstur mucoid dikarenakan adanya zat polisakarida yang terkandung pada komponen ekstraselular khamir. Berdasarkan Fardiaz (1992), beberapa khamir ditutupi oleh komponen ekstraselular berupa polisakarida dan heteropolisakarida yang berlendir.

Pengamatan mikroskopik khamir berumur 48 jam dalam medium Yeast Malt Agar (YMA) pada suhu $27-28^{\circ} \mathrm{C}$ menunjukkan tipe pertunasan monopolar, bentuk sel bulat hingga oval dan tidak terdapat hifa ataupun pseudahifa pada khamir. Tipe pertunasan monopolar adalah tipe dengan tunas (bud) yang muncul 
pada satu sisi dari bagian sel.

\section{PENGAMATAN MAKROSKOPIK DAN MIKROSKOPIK KAPANG}

Kapang yang diamati adalah dari genus Aspergillus sp., Fusarium sp., dan Penicillium sp. Kapang tersebut merupakan kapang yang diisolasi dari pakan ternak ayam asal Bogor. Pengamatan morfologi kapang dilakukan ketika kapang telah bersporulasi penuh (umur 7 hari) dalam medium Malt Extract Agar (MEA) dan diinkubasi pada suhu $27-28^{\circ} \mathrm{C}$

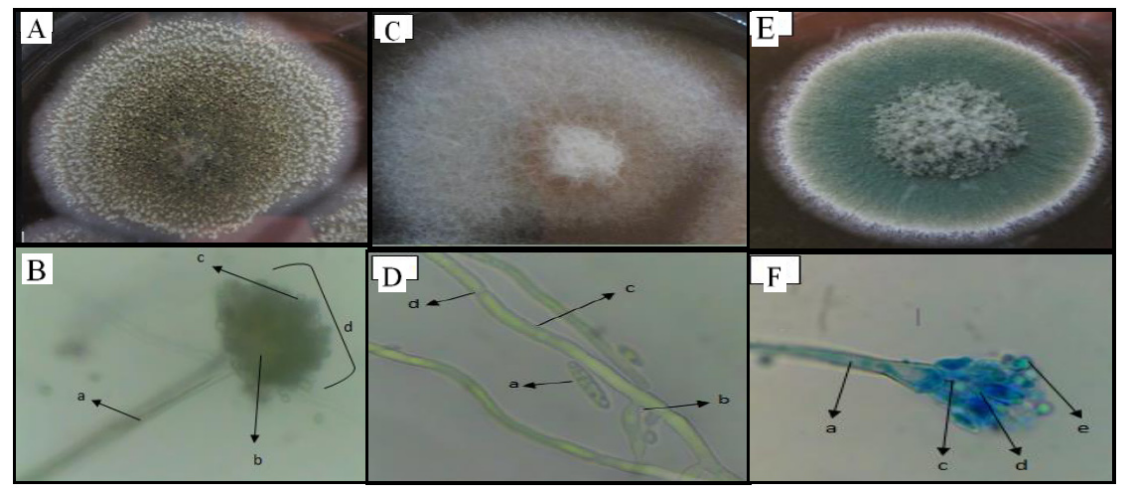

Gambar 2. Pengamatan koloni kapang (A). makroskopik kapang Aspergillus, (B) mikroskopik kapang Aspergillus perbesaran 1000x ( $a=$ konidiofor, $b=$ vesikel, $c=$ konidia, $d=$ kepala konidia), $(C)$ makroskopik kapang Fusarium sp., (D) Mikroskopik kapang Fusarium sp. perbesaran 1000x ( $a=$ makrokonidia, $b=$ percabangan hifa, $c=$ hifa, $d=$ sekat pada hifa), (E). makroskopik kapang Penicillium sp., (F) Mikroskopik kapang Penicillium sp. perbesaran 1000x $(\mathrm{a}=$ konidiofor, $\mathrm{c}=$ metula, $\mathbf{d}=$ fialid, $\mathrm{e}=$ konidia) [Sumber: Dokumentasi pribadi] .

Hasil pengamatan koloni dari genus Aspergillus sp. menunjukkan koloni kapang berwarna cedar green dengan tepi ivory, tekstur granula, memiliki exudate drops, growing zone, zonasi dan radial furrow, warna sebalik koloni van dyck brown. Pada pengamatan mikroskopik, genus Aspergillus sp. terdapat konidiofor, vesikel, kepala konidia dan konidia. Berdasarkan Klich (2002), pengamatan koloni Aspergillus sp. secara mikroskopis diantaranya: memiliki hifa yang bersekat, pada ujung konidiofor membulat membentuk vesikel, metula dan fialid. Pada ujung fialid dihasilkan konidia yang berbentuk bulat.

Hasil pengamatan koloni dari genus Fusarium sp. menunjukkan koloni kapang berwarna Light fresh atau dengan bercak merah muda dan bertekstur granula dan seperti kapas, tekstur tidak bergranula, memiliki growing zone dan zonasi, tidak memiliki radial furrow dan exudat drop, warna sebalik koloni cinnamon. Pada pengamatan mikroskopik, koloni Fusarium sp. memiliki karaktersitik yaitu hifa bersekat, memiliki makrokonida yang berbentuk seperti bulan sabit. Morfologi koloni genus Fusarium sp. sesuai dengan deskripsi menurut Listiandini (2011) kapang Fusarium sp. memiliki bentuk miselium seperti kapas dan tumbuh cepat dengan bercak-bercak berwarna merah muda, abu-abu, atau kuning. Beberapa jenis Fusarium sp. memiliki dua bentuk dasar konidia yaitu mikrokonidia dan makrokonidia, bersepta (Barnett dan Hunter, 1998).

Hasil pengamatan koloni dari genus Penicillium sp. menunjukkan koloni kapang berwarna night green dengan tepi berwarna white, tekstur bergranula, memiliki growing zone, exudat drop dan zonasi, tidak memiliki radial furrow, warna sebalik koloni brunt ochre. Pada pengamatan mikroskopik, koloni Penicillium sp. memiliki karakteristik yaitu hifa bersekat, memiliki percabangan pada ujung konidiofor, memiliki metula dan fialid. Morfologi koloni genus 
Penicillium sp. sesuai dengan deskripsi menurut Gams et al., (1987) koloni Penicillium sp. biasanya berwarna hijau, terkadang putih, sebagian besar memiliki konidiofor, falid, dan metula. Konidiofor tunggal (mononematus) atau majemuk (synematous).

\section{ENUMERASI KHAMIR DAN SPORA KAPANG}

Enumerasi khamir dan spora atau hifa kapang dilakukan dengan metode Total Plate Count (TPC). Enumerasi khamir dan spora atau hifa kapang bertujuan untuk mempersiapkan jumlah inokulum yang seragam untuk digunakan pada pengujian antagonisme. Hasil enumerasi menunjukkan jumlah dari koloni khamir lebih tinggi dibandingkan jumlah spora atau hifa kapang. Jumlah koloni dari sebelas biakan khamir berada pada kiasaran $(1,3-2,1) \times 10^{8} \mathrm{CFU} /$ $\mathrm{ml}$ dan jumlah spora dari tiga biakan kapang asal pakan ternak ayam berada pada kisaran $(0,28 \times 1,1) \times 10^{7} \mathrm{CFU} /$ $\mathrm{ml}$.

Penggunaan jumlah sel khamir yang lebih tinggi dibandingkan dengan jumlah spora kapang dalam medium memberikan kesempatan pada khamir untuk berkompetisi dengan kapang dalam memperoleh nutrien dan ruang. Manso \& Nunes (2011), melaporkan inokulasi khamir Metschnikowia andauensis dengan jumlah sel $1 \times 10^{7} \mathrm{CFU} /$ $\mathrm{ml}$ mampu menghambat pertumbuhan dari kapang Pen.expansum dengan jumlah $1 \times 10^{4} \mathrm{CFU} / \mathrm{ml}$ sebesar $90 \%$ pada buah apel pasca panen. Pada penggunaan jumlah sel khamir sebesar $1 \times 10^{6} \mathrm{CFU} / \mathrm{ml}$ hanya mampu menghambat pertumbuhan kapang P.expansum dengan jumlah sel $1 \times 10^{4} \mathrm{CFU} / \mathrm{ml}$ sebesar $38 \%$.

\section{PENGUJIAN ANTAGONISME DENGAN METODE CO-CULTURE}

\section{Pengamatan Pertumbuhan Khamir dan Kapang Kontrol}

Hasil pengamatan kontrol khamir dalam medium PDB selama empat hari menunjukkan adanya pertumbuhan sel khamir. Pertumbuhan khamir pada medium cair ditunjukkan karena adanya perbuhan warna pada medium menjadi keruh, terbentuknya endapan, terbentuknya pelikel, dan tidak adanya pertumbuhan hifa atau miselium kapang. Hasil pengamatan pertumbuhan koloni kapang yang diinokulasikan menunjukkan adanya keberadaan lapisan miselium di permukaan medium.

Kontrol khamir mengalami pertumbuhan yang baik pada medium PDB. Hal ini dikarenakan pertumbuhan khamir pada medium cair dapat membentuk endapan, pelikel dan tidak adanya pertumbuhan hifa atau miselium kapang pada medium pertumbuhannya. Sjamsuridzal (2007) menyatakan bahwa pertumbuhan khamir pada medium cair dapat ditunjukkan dari pembentukan endapan biomasa pada dasar labu erlenmeyer dan pelikel yang berada pada tepi labu erlenmeyer.

Hasil pengamatan pertumbuhan koloni kapang yang diinokulasikan pada medium PDB pada kontrol menunjukkan adanya keberadaan lapisan miselium di permukaan medium. Miselium kapang genus Aspergillus sp. pada pada hari ke-3 berwarna putih dengan spora berwarna kecokelatan. Pengamatan pada kontrol kapang Fusarium sp. menunjukkan terbentuknya lapisan miselium pada permukaan medium pada hari ke-3. Pengamatan pada kontrol koloni kapang Penicillium sp. menunjukkan terbentuknya lapisan miselium pada permukaan medium pada hari pertama. Miselium kapang berwarna putih dengan spora berwarna kehijauan. Pertumbuhan kapang Aspergillus sp., Fusarium sp., dan Penicillium sp. pada medium PDB menyebabkan medium tersebut mengalami kekeruhan.

\section{Pengamatan Morfologi Khamir dan Kapang Perlakuan}

Hasil pengamatan menunjukkan sebanyak 8 isolat khamir berpotensial dalam menghambat pertumbuhan kapang Aspergillus sp., 7 isolat khamir berpotensial dalam menghambat pertumbuhan kapang dari genus Fusarium 
sp., 6 isolat khamir berpotensial dalam menghambat pertumbuhan kapang dari genus Penicillium sp. Dari pengujian sebelas isolat khamir dengan menggunakan metode co-culture, didapatkan sebanyak 5 khamir dengan kode isolat $\mathrm{T}_{3} \mathrm{D}_{2} \mathrm{DU}$ 1.7, $\mathrm{T}_{4} \mathrm{D}_{2} \mathrm{WU}_{2} \mathrm{~J}_{2}, \mathrm{~T}_{4} \mathrm{D}_{2}$-DU 2.1, $\mathrm{T}_{4} \mathrm{D}_{1} \mathrm{DU} 2.1, \mathrm{~T}_{5} \mathrm{D}_{1} \mathrm{DU} 2.2$ yang paling potensial dalam menghambat pertumbuhan hifa dan miselium kapang Aspergillus sp., Fusarium sp., dan Penicillium sp.

Biakan khamir diinokulasikan delapan jam lebih awal pada medium PDB daripada biakan kapang. Hal tersebut dilakukan untuk memberikan keuntungan kepada khamir dalam hal adaptasi medium, perolehan nutrien, dan perolehan ruang hidup. Ketika suspensi kapang diinokulasikan ke dalam medium yang sudah ditumbuhi oleh biakan khamir, maka nutrien dan ruang yang tersedia pada media telah berkurang. Hal tersebut dapat mengakibatkan pembentukan hifa atau miselium dan juga sporulasi menjadi terhambat. Zhao et al., (2008) melaporkan bahwa interval waktu inokulasi khamir Pichia guillermondii lebih awal 24, 12, dan 6 jam dari inokulasi kapang Rhizopus nigricans pada buah tomat, akan memberikan kesempatan khamir P. guillermondii untuk beradaptasi pada substrat, memanfaatkan nutrien dan ruang hidup pada medium yang ada.

\section{KESIMPULAN}

Lima isolat khamir $\left(\mathrm{T}_{3} \mathrm{D}_{2} \mathrm{DU}\right.$ 1.7, $\mathrm{T}_{4} \mathrm{D}_{2} \mathrm{WU}_{2}, \mathrm{~T}_{4} \mathrm{D}_{2}-\mathrm{DU}$ 2.1, $\mathrm{T}_{4} \mathrm{D}_{1} \mathrm{DU}$ 2.1, $\mathrm{T}_{5} \mathrm{D}_{1} \mathrm{DU}$ 2.2) mampu menghambat pertumbuhan isolat kapang dalam pengujian antagonisme menggunakan metode co-culture.

\section{DAFTAR PUSTAKA}

Angulo, F.J., J. A. Nunnery \& H.D. Blair. (2004). Antimicrobial resistance in zoonotic enteric pathogens. Rev. Sci. Tech. Off. Int. Epiz. 23 (2): 485-496.

Barnett,H.L.\& B.B. Hunter. (1998). Illustrsted geners of imperfact fungi. 4th ed. APS PRESS The American Phytopathological society St.Paul, Minnesota: $218 \mathrm{hlm}$.

Benson, H.J. (2001). Microbiological application: Laboratory manual in general microbiology. The McGraw-Hills Company, Inc. New York: 478 hlm.

Cappuccino, J. G. \& N. Sherman. (2001). Microbiology A Laboratory Manual. 6th ed. Rockland Community College, New York.

Fardiaz, S. (1992). Mikrobiologi Pangan 1. PT Gramedia Pustaka Utama: Jakarta

Gandjar, I., R.A. Samson, K. van den Tweel-Vermeulen, A. Oetari, \& I. Santoso. (1999). Pengenalan kapang tropik umum. Yayasan Obor Indonesia. Jakarta: $136 \mathrm{hlm}$.

Klich, M.A. (2002). Identification of common Aspergillus species. Central bureau Voor Schimmelcultures, Utrecht, Netherlands: $116 \mathrm{hlm}$.

Lindow, S. E. \& M. T. Brandl. (2003). Minireview microbiology of the phyllosphere. App and Enviro Microbiol : 1875-1883.

Manso, TZ. \& C. Nunes. (2011). Metschnikowia andauensis as a new biocontrol agent of fruit postharvest diseases. Post Biol. Echnol. 64-71.

Pimenta, R.S., F. L Silva, J. F. M. Silva, P. B. Morais, D. T. Braga, C. A. Rosa, \& A. Correa Jr. (2007). Biological Control Of Penicillium itlicum, P. digitatum and P. expansum By The Predacious Yeast Saccharomycopsis schoenii On 
Oranges. Braz. J of Microbiol: 85-90.

Samson, R. A., S. Hoekstra, \& J.C. Frisvad. (2004). Introduction to food and airborne fungi. Centraalbureau Voor Schimmelcultures, Utrecht: $383 \mathrm{hlm}$

Sharma, A., V.K. Patel, \& P. Ramteke. (2009). Identification of vibrocidal compound from medical plant. World. J. Microbiol. Biotehnol: 19-25.

Sjamsuridzal, W. (2007). Yeast diversity and conservation Gunung Halimun National Park, Indonesia. Nagao Natural Environment Foundation, Depok: $254 \mathrm{hlm}$.

Suci., R. (2012). Isolasi dan Identifikasi Secara Konvensional Khamir dari Tanaman Jati (Tectona grandis L.f.) di Desa Cibungur, Purwakarta. Skripsi. Biologi. Universitas Negeri Jakarta.

Sukmawati, D. (2014). Khamir Asal Tumbuhan Saeh (Broussonetia papyrifera) dan Potensinya Sebagai Agan Biokontrol Kapang pada Buah Tomat Pascapanen. Disertasi. Universitas Indonesia. $243 \mathrm{hlm}$.

Suprijatna, E., A. Umiyati, \& K. Ruhyat. (2005). Ilmu Dasar Ternak Unggas. Jakarta. Penebar Swadaya.

Zhao Y., K. Tu, X. Shao, W. Jing \& Z. Su. (2008). Effects of the yeast Pichia guilliermondii against Rhizopus nigricans on tomato fruit. Postharvest Biol. Technol: 113-120. 